\title{
Impaired Cognition after Stimulation of P2Y, Receptors in the Rat Medial Prefrontal Cortex
}

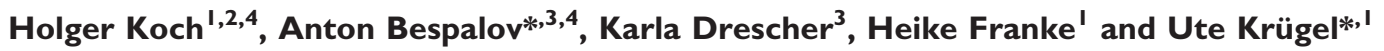 \\ 'Rudolf-Boehm Institute of Pharmacology and Toxicology, University of Leipzig, Härtelstrasse 16-18, Leipzig, Germany; ${ }^{2}$ Translational Centre for \\ Regenerative Medicine (TRM) Leipzig, University of Leipzig, Philipp-Rosenthal-Strasse 55, Leipzig, Germany; ${ }^{3}$ AbbVie, Neuroscience Research, \\ Knollstrasse 50, Ludwigshafen, Germany
}

\begin{abstract}
We hypothesize that cortical ATP and ADP accumulating in the extracellular space, eg during prolonged network activity, contribute to a decline in cognitive performance in particular via stimulation of the G protein-coupled P2Y, receptor (P2Y, R) subtype. Here, we report first evidence on P2Y, R-mediated control of cognitive functioning in rats using bilateral microinfusions of the selective agonist MRS2365 into medial prefrontal cortex (mPFC). MRS2365 attenuated prepulse inhibition of the acoustic startle reflex while having no impact on startle amplitude. Stimulation of $\mathrm{P}_{2} \mathrm{Y}_{1}$ Rs deteriorated performance accuracy in the delayed non-matching to position task in a delay dependent manner and increased the rate of magazine entries consistent with both working memory disturbances and impaired impulse control. Further, MRS2365 significantly impaired performance in the reversal learning task. These effects might be related to MRS2365evoked increase of dopamine observed by microdialysis to be short-lasting in MPFC and long-lasting in the nucleus accumbens. P2Y, Rs were identified on pyramidal cells and parvalbumin-positive interneurons, but not on tyrosine hydroxylase-positive fibers, which argues for an indirect activation of dopaminergic afferents in the cortex by MRS2365. Collectively, these results suggest that activation of P2Y, Rs in the mPFC impairs inhibitory control and behavioral flexibility mediated by increased mesocorticolimbic activity and local disinhibition. Neuropsychopharmacology (2015) 40, 305-3।4; doi: I0.1038/npp.20I4.173; published online 20 August 20I4
\end{abstract}

\section{INTRODUCTION}

In the central nervous system adenosine $5^{\prime}$-triphosphate (ATP) is released in an activity dependent manner from neurons and glia cells into the extracellular space (Bodin and Burnstock, 2001; Pankratov et al, 2006; Heinrich et al, 2012). Its concentration increases notably under specific physiological states such as neural network oscillations (Khakh et al, 2003) but also after psychostimulant drug administration (Pintor et al, 1995) or during a variety of pathological conditions such as oxygen-glucose deprivation, epilepsy, neuroinflammation or neuronal injury (Burnstock et al, 2011) known to have impact on cognitive functions.

Once released into the extracellular space, ATP together with some of its breakdown products (eg adenosine $5^{\prime}$ diphosphate; ADP) acts at purine receptors (P2Rs) classified into several subtypes of ligand-gated cationic channels (P2X) and G protein-coupled receptors (P2Y) on the basis of their function, pharmacology and molecular cloning

\footnotetext{
*Correspondence: A Bespalov, AbbVie Deutschland $\mathrm{GmbH}$ \& Co KG, Neuroscience Research, Knollstrasse 50, Ludwigshafen 67008, Germany or Dr $\cup$ Krügel, Rudolf-Boehm Institute of Pharmacology and Toxicology, University of Leipzig, Haertelstrasse 16-18, Leipzig 67061, Germany, Tel: +49 34l 97 24600, Fax: +49 3419724609 , E-mail: anton.bespalov@abbvie.com or

Ute.Kruegel@medizin.uni-leipzig.de

${ }^{4}$ These authors contributed equally to this work.

Received 19 May 2014; revised 2 July 20।4; accepted 10 July 20।4; accepted article preview online 15 July 2014
}

(Abbracchio et al, 2009; Fischer and Krügel, 2007). Certain effects of ATP and ADP analogues, locally applied to the ventral striatum or ventral tegmentum, on behaviors in rats are attributed to stimulation of P2YR in mesolimbic circuits, in particular to the $\mathrm{P} 2 \mathrm{Y}_{1} \mathrm{R}$ subtype which is expressed, eg on dopamine neurons, and preferentially recognizes ADP over ATP (Waldo and Harden, 2004; Kittner et al, 2004; Krügel et al, 2001a).

With prolonged network activity (eg associated with performance of a certain cognitive task), levels of ATP and its breakdown products may accumulate in the extracellular space and be responsible for a decline in performance (ie fatigue). Given that local stimulation of P2YR facilitates dopaminergic neurotransmission and $\mathrm{P} 2 \mathrm{Y}_{(1)} \mathrm{R}$ antagonists suppress dopamine in basal ganglia as previously shown, we expected that $\mathrm{P} 2 \mathrm{Y}_{1} \mathrm{R}$ will affect dopamine release in cortical areas as well (Chandaka et al, 2011; Kittner et al, 2004; Krügel et al, 2001a). Knowing the importance of cortical dopaminergic signaling for performance of various cognitive tasks, we hypothesized that stimulation of $\mathrm{P} 2 \mathrm{Y}_{1} \mathrm{Rs}$ will affect cognitive behaviors, which depend on the prefrontal cortical function (Floresco et al, 2009; Arnsten, 2009).

The medial prefrontal cortex (mPFC) has attracted increasing attention because it is responsible for highly specialized complex cognitive functions such as planning of goal-directed actions, problem-solving and predicting forthcoming events, and because of its relevance for clinical cognitive impairment associated with schizophrenia, 
depression, attention deficit hyperactivity disorder or drug addiction (Arnsten and Rubia, 2012; Goldstein and Volkow, 2011; Lüscher and Malenka, 2011). The generation of appropriate goal-directed behavior relies, among others, on the intact interaction of the dorsolateral PFC and anterior cingulate cortex in primates, analogous to the rodent $\mathrm{mPFC}$, with subcortical structures including the ventral tegmental area (VTA), striatum including nucleus accumbens (NAc) and other parts of the mesocorticolimbic circuit (Chudasama, 2011; Seamans et al, 2008).

In ex vivo and in vitro investigations ATP/ADP are important contributors to the regulation of prefrontal cortical activity. Functional postsynaptic $\mathrm{P}_{2} \mathrm{Y}_{1} \mathrm{Rs}$ were found on layer $\mathrm{V}$ pyramidal neurons of rat $\mathrm{mPFC}$ (Luthardt et al, 2003). In these neurons, activation of P2 ${ }_{1}$ R by ATP/ADP inhibits long-term depression (LTD), a synaptic plasticity phenomenon implicated in long-term memory, via reduction of $\mathrm{Ca}^{2+}$-influx through voltagesensitive $\mathrm{Ca}^{2+}$-channels (Guzman et al, 2010). Therefore, in line with our hypothesis, one can expect modulatory effects of $\mathrm{P} 2 \mathrm{Y}_{1} \mathrm{Rs}$ on aspects of cognitive and executive functions involving attention, working memory, decision making, and the executive control of behavior, eg cognitive flexibility and adaptation.

To explore whether stimulation of $\mathrm{P} 2 \mathrm{Y}_{1} \mathrm{Rs}$ affects such prefrontocortical functions, we investigated behavioral effects of local administration of $(N)$-methanocarba-2MeSADP (MRS2365), a highly potent selective non-nucleotide $\mathrm{P} 2 \mathrm{Y}_{1} \mathrm{R}$-agonist with an $\mathrm{EC}_{50}=1.2 \mathrm{nM}$. At concentrations up to 1 and $10 \mu \mathrm{M}$, MRS2365 did not activate or inhibited either $\mathrm{P}_{2} \mathrm{Y}_{12}$ or $\mathrm{P}_{2} \mathrm{Y}_{13}$ receptors, respectively (Chhatriwala et al, 2004), nor hints for pharmacological relevant affinity at other targets exist.

Further, using dual-probe microdialysis, we provide evidence that the stimulation of prefrontal $\mathrm{P}_{2} \mathrm{Y}_{1}$ Rs by local infusion of MRS2365 influences mesocorticolimbic dopamine as a possible mechanism contributing to its behavioral effects. Immunohistochemical studies provide evidence, that the behavioral and neurochemical effects of MRS2365 may partly be mediated by $\mathrm{P}_{2} \mathrm{Y}_{1}$ Rs expressed on GABAergic interneurons.

\section{METHODS AND MATERIALS}

\section{Animals}

44 male Wistar rats for behavioral experiments and 10 for immunohistochemistry (Janvier Labs, Le Genest Saint Isle, France; 200-300 g body weight) as well 18 male SpragueDawley rats for microdialysis (Charles River, Bad Sulzfeld, Germany; 280-380 g body weight) were housed under standard conditions with free access to food and water and a $12 \mathrm{~h}$ light-dark cycle with lights on from 7:00 a.m. After implantation of the guide cannulae, animals were housed individually. Two days before training for delayed non-matching to position (DNMTP) and reversal learning tasks, rats were housed individually and restricted to $15 \mathrm{~g}$ food per day. Experiments were approved by the local governmental bodies according to the European Communities Council Directive (86/609/EEC) and Animal Welfare Offices (AbbVie Deutschland GmbH \& Co KG and Landesdirektion Sachsen, Leipzig).

\section{Bilateral Drug Infusion}

MRS2365 [(1R,2R,3S,4R,5S)-4-[6-Amino-2-(methylthio)-9H-purin-9-yl]-2,3-dihydroxybicyclo[3.1.0]hex-1-yl]methyl] diphosphoric acid mono ester trisodium salt; Tocris, Ellisville, U.S.A.) was dissolved in artificial cerebral spinal fluid (ACSF, in $\mathrm{mM}$ : $126 \mathrm{NaCl} ; 2.5 \mathrm{KCl} ; 1.2 \mathrm{NaH}_{2} \mathrm{PO}_{4} ; 1.3 \mathrm{MgCl}_{2}$ and $2.4 \mathrm{CaCl}_{2} ; \mathrm{pH}$ 7.4). Bilateral guide cannulae implanted into the $\mathrm{mPFC}(\mathrm{AP}=3.2 \mathrm{~mm}, \mathrm{~L}= \pm 1.5 \mathrm{~mm}, \mathrm{~V}=3.1 \mathrm{~mm}$ relative to bregma at an angle of $15^{\circ}$ ) and fixed with dental cement (see Supplementary Material) were used to apply a bolus of $0.5 \mu \mathrm{l}$ MRS2365 $(0.05 \mathrm{pmol})$, or ACSF was infused bilaterally into the $\mathrm{mPFC}(0.2 \mu \mathrm{l} / \mathrm{min})$. This dose of MRS2365 was selected by pilot dose-response and antagonist studies in the open field novelty as a primary test for biological activity and confirming the $\mathrm{P} 2 \mathrm{Y}_{1} \mathrm{R}$ selectivity (Supplementary Material, Supplementary Figure S2). Latin Square design was applied for pseudo-random order of ACSF and MRS2365 application in PPI $(n=14)$ and DNMTP $(n=10)$ experiments. At least two training sessions without treatment were performed between drug tests in DNMTP experiments. In PPI experiments, the second treatment session followed after two days. In the reversal learning task, animals received drug applications immediately prior to the sessions of retention and reversal phase.

\section{Prepulse Inhibition (PPI) of the Acoustic Startle Response (ASR)}

PPI was measured in a startle chamber (TSE, Bad Homburg, Germany) equipped with a movement-sensitive piezoelectric platform and two loudspeakers (Schneider et al, 2005). After $6 \mathrm{~min}$ habituation at continuous background sound pressure level (SPL) of $65 \mathrm{~dB}$, the animals received 15 initial startling pulses of $110 \mathrm{~dB}$ for $24 \mathrm{~ms}$ followed by 20 pseudo-randomly ordered trials of 10 different types: pulse alone; control (without stimulus); prepulse alone $(68 \mathrm{~dB}, 70 \mathrm{~dB}, 78 \mathrm{~dB}$ or $84 \mathrm{~dB})$; pulse with preceding prepulse (prepulse $68 \mathrm{~dB}, 70 \mathrm{~dB}, 78 \mathrm{~dB}$ or $84 \mathrm{~dB}$ each $100 \mathrm{~ms}$ before the pulse) with an inter-stimulus interval between 4000 and $14000 \mathrm{~ms}$ followed by 5 startling pulses to analyze habituation. PPI was calculated as \% reduction of the ASR amplitude at a given prepulse intensity $(100 \times($ mean startle response without prepulse - mean startle response with prepulse)/mean startle response without prepulse). Habituation was calculated as percentage of ASR from 15 initial pulses to 5 final startle pulses. ACSF or MRS2365 were administered immediately before the test.

\section{Delayed Non-Matching to Position (DNMTP) Task}

Experiments were conducted in operant chambers (MED Associates, East Fairfield, U.S.A.) (Sukhotina et al, 2008). Rats were trained to lever-press for food and to learn the DNMTP rule. At start of each trial, randomly one of two levers was presented ('sample') and retracted after it was pressed. Following a variable delay $(0,8$ or $16 \mathrm{~s})$ the rat had to nose-poke for presentation of both levers. If the animal pressed the non-matching lever (opposite to 'sample'), it was a correct response, both levers were retracted, the food magazine was illuminated and the animal was rewarded. If the 'sample' lever (matching) was pressed again, a non-rewarded 
incorrect response was recorded. Each of the 96 trials was followed by an inter-trial interval of $5 \mathrm{~s}$ with house light on. After $20 \mathrm{~s}$ given to respond, the lever was retracted and the house light extinguished for $20 \mathrm{~s}$. Failure to respond was recorded as omission. This DNMTP training took 4 weeks to reach criteria of: $(1) \geqslant 90 \%$ correct without delay, $(2) \geqslant 50 \%$ correct at $16 \mathrm{~s}$ delay, (3) between $40-60 \%$ lefthand side performance and (4) no or few omissions. Total choice accuracy, latency to press 'sample' lever (latency to sample), latency to take reward from food magazine (magazine latency), total number of nose-pokes, magazine entries, omissions, rewards as well as session length, lefthand side performance and failures to collect reward were analyzed. Choice accuracy was calculated for 'same trials' (expected correct response was the same as during the preceding trial) and 'different trials' (expected correct response was different from the one in the preceding trial). Once training criteria were met, tests were conducted with MRS2365 or vehicle applied immediately before the session.

\section{Reversal Learning Task}

The procedure was adapted as previously described (Boulougouris and Robbins, 2010). Rats $(n=20)$ were shaped to nose-poke into the food magazine to initiate presentation of two levers and to respond on the individually defined correct lever, first under a fixed ratio (FR) 1 (one lever press for reward), later under FR3. Completion of FR3 requirements at correct lever, but not at incorrect lever, resulted in delivery of a single reward pellet. Responding on either lever was followed by retraction of both levers and by deactivation of house light for $5 \mathrm{~s}$. One session consisted of a maximum of five blocks with 10 trials each. The rat had to nose-poke into the food magazine within $20 \mathrm{~s}$ to trigger presentation of the levers. There was a 10-s response window after the presentation of levers. Failure to respond resulted in termination of the trial recorded as omission.

Rats were trained once a day until the criterion of at least nine correct trials in one block was achieved. If the criterion was not achieved, this step was repeated the next day. After rats achieved the criterion, this step was repeated next day under drug application (retention). When they fulfilled the criterion under drug application, an initial retention phase until criterion was repeated next day followed by a shift of position of the reinforced lever (within-session reversal) and the same criterion was applied. Reversal learning continued, if necessary, during the subsequent days. Percentage of correct trials, sessions to reach criterion and omissions were analyzed.

\section{Microdialysis}

The effect of prefrontocortical perfused MRS2365 on extracellular dopamine in this area and in the NAc was investigated by microdialysis (Krügel et al, 2003; Nikiforuk et al, 2010). Briefly, microdialysis probes (CMA/12, $3 \mathrm{~mm}$ length, $20 \mathrm{kDa}$ cut-off, guide cannulae $\mathrm{mPFC}$ : $\mathrm{AP}=3.2 \mathrm{~mm}$, $\mathrm{L}=0.6 \mathrm{~mm}, \mathrm{~V}=0.2 \mathrm{~mm}$; NAc: $\mathrm{AP}=1.7 \mathrm{~mm}, \mathrm{~L}=1.3 \mathrm{~mm}$, $\mathrm{V}=3.7 \mathrm{~mm}$ ) were perfused with ACSF simultaneously in both areas $(1.5 \mu \mathrm{l} / \mathrm{min})$ or MRS2365 in the MPFC as indicated in Figure 4. Dialysates for baseline dopamine were taken beginning one hour after perfusion of probes and analyzed for dopamine after separation by HPLC by electrochemical detection (for more details see Supplementary Material).

\section{Multiple Immunofluorescence}

Double immunofluorescence labeling studies were performed as previously described (Franke et al, 2006). Slices were incubated with an mixture of mouse anti-microtubule associated protein-2 (MAP2, 1:1000, Chemicon), mouse anti-glial fibrillary acidic protein (GFAP, 1:1000, Sigma), mouse anti- $\gamma$-aminobutyric acid (GABA, 1:1000, Sigma), mouse anti-tyrosine hydroxylase ( $\mathrm{TH}, 1: 1000$, Chemicon), mouse anti-synaptophysin (1:200, Sigma) or mouse antiparvalbumin (1:1000, Sigma) and rabbit anti-P2Y ${ }_{1} \mathrm{R}(1: 400$, Alomone Labs). Visualization was performed with a mixture of carbocyanine (Cy) 2-conjugated goat anti-mouse IgG and Cy3-conjugated goat anti-rabbit IgG. In experiments with rabbit anti-calretinin (1:1000, swant) a goat anti$\mathrm{P}_{2} \mathrm{Y}_{1} \mathrm{R}$ antibody (1:1000, Santa Cruz Biotechnology) was used followed by visualization with Cy2-conjugated donkey anti-rabbit and horse anti-goat IgG $(20 \mu \mathrm{g} / \mathrm{ml}$ in TBS containing 2\% BSA each).

For triple immunofluorescence a mixture of rabbit anti$\mathrm{P}_{2} \mathrm{Y}_{1} \mathrm{R}$ (1:400), guinea pig anti-subtype 3 vesicular glutamate transporter (vGLUT3; $1: 300$ in 5\% normal donkey serum in TBS, containing $0.3 \%$ Triton $\mathrm{X}-100$ ) and mouse anti-MAP2 (1:1000) was applied overnight. After washing the sections were incubated with a mixture of Cy2-antiguinea pig, Cy3-anti-rabbit and Cy5-anti-mouse IgG (all $20 \mu \mathrm{g} / \mathrm{ml}$ ) for $1 \mathrm{~h}$ and washed again. Immunofluorescence was investigated with a confocal laser scanning microscope (LSM 510 Meta, Zeiss, Oberkochen, Germany). No immunofluorescence was observed without the primary $\mathrm{P}_{2} \mathrm{Y}_{1} \mathrm{R}$ antibody or by pre-adsorption of the antibody with the peptides used for their generation.

\section{Statistical Analysis}

Data are presented as mean \pm SEM. Effects of MRS2365 on the reversal task performance and ASR were evaluated using one-way analysis of variance (ANOVA). Effects of MRS2365 on the DNMTP task performance, PPI and dopamine microdialysis were analyzed using a set of one- and twoway ANOVAs with repeated measures and post hoc Tukey's test. Rank transformation preceded DNMTP data analysis by ANOVA.

\section{RESULTS}

\section{Prepulse Inhibition (PPI) of the Acoustic Startle Response (ASR)}

Treatment with MRS2365 (0.05 pmol) did not affect ASR amplitude during 'pulse only' trials and had no impact on habituation to repeated presentation of startle pulses (Figure 1a and b). MRS2365 had an overall attenuating effect on PPI (treatment: $F_{1,24}=7.66, P=0.01$, Figure 1c). This effect was seen only at low-to-intermediate prepulse intensities (treatment $\times$ PPI interaction: $\mathrm{F}_{3,72}=2.84$, $P=0.04$; Figure 1c). MRS2365 had no effects on startle 

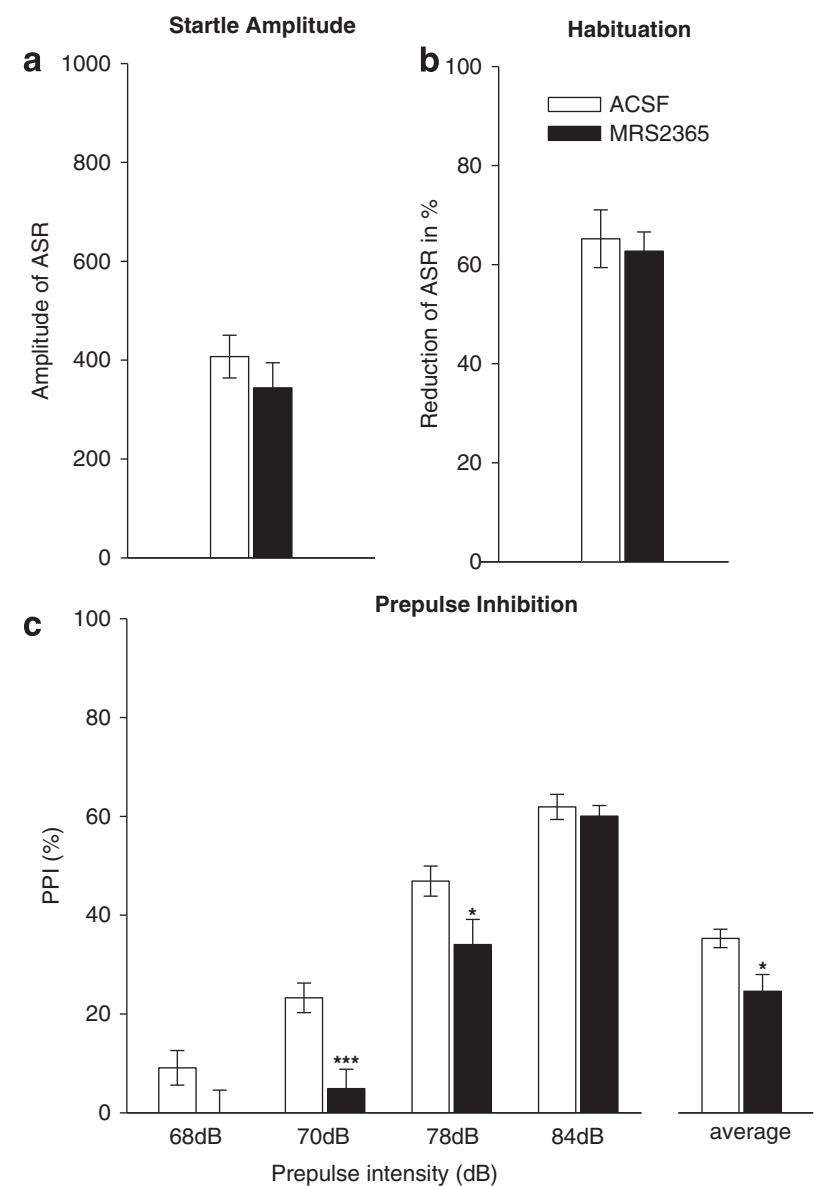

Figure I Effects of MRS2365 on the startle amplitude (a), startle habituation (b) and PPI of the ASR dependent on prepulse intensity (c) in comparison to ACSF-microinjected animals. MRS2365 was applied bilaterally into the mPFC at a dose of $0.05 \mathrm{pmol} / \mathrm{side}$, ACSF was given in the equivalent volume of $0.5 \mu \mathrm{l}$. Data are presented as mean $\pm \operatorname{SEM}(n=13$ each). $* P<0.05$, $* * * P<0.001$ versus ACSF.

response latencies, duration of responses, time to maximal response or on startle responses induced by prepulses (not shown).

\section{Delayed Non-Matching to Position (DNMTP) Task}

Under treatment with ACSF, performance accuracy was above $90 \%$ at low delays, but gradually reduced to nearchance levels as delays increased to $16 \mathrm{~s}$. MRS2365 $(0.05 \mathrm{pmol})$ reduced overall accuracy at 8 and $16 \mathrm{~s}$ delay (delay by treatment interaction: $\mathrm{F}_{2,59}=5.1, P<0.05$; effect of treatment: $\mathrm{F}_{1,59}=40.3, P<0.001$; effect of delay: $\mathrm{F}_{2,59}=52.5$, $P<0.001$; Figure 2a). This impairment was also evident during the trials where the correct lever was different from that in the preceding trial (delay by treatment interaction: $\mathrm{F}_{1,9}=3.8, \quad P=0.04 ; \quad$ effect of treatment: $\mathrm{F}_{1,59}=35.2$, $P<0.001$; effect of delay: $\mathrm{F}_{2,59}=41.2, P<0.001$; Figure $2 \mathrm{c}$ ). For the 'same' lever trials, there were significant main effects of treatment $\left(\mathrm{F}_{1,59}=8.25, P<0.05\right)$ and delay $\left(\mathrm{F}_{2,59}=25.3, P<0.001\right)$ but no delay by treatment interaction (Figure $2 \mathrm{~b}$ ).

MRS2365 also shortened the session length $\left(\mathrm{F}_{1,9}=5.54\right.$, $P=0.04$ ), increased the frequency of magazine entries $\left(\mathrm{F}_{1,9}=8.56, P=0.02\right)$. MRS2365 had no effect on total omissions, latency to sample, magazine latency, reward, left-hand side performance, failure to collect food and the correct response latency (Supplementary Table S1).

\section{Reversal Learning Task}

Prior to MRS2365 treatment, the groups did not differ in task acquisition (Figure 3a). Treatment with MRS2365 did not influence the performance in the retention phase (Figure $3 \mathrm{~b}$ ) but resulted in a reduced percentage of correct trials during the reversal phase $\left(\mathrm{F}_{1,17}=9.43, P<0.01\right.$; Figure 3c). ACSF-treated rats needed less sessions to the
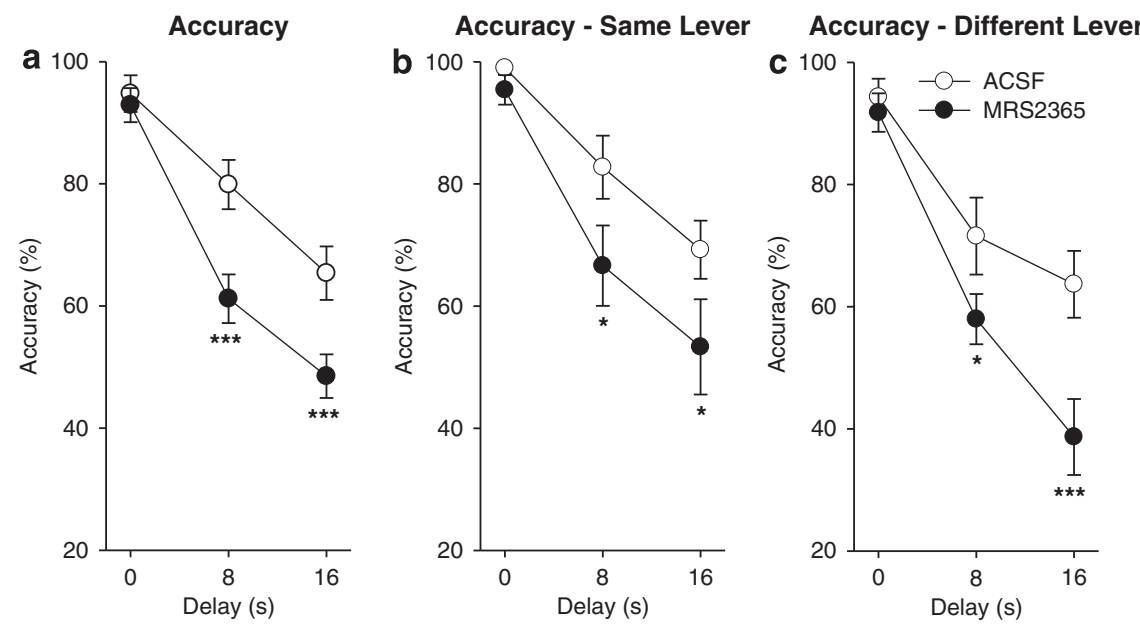

Figure 2 Effects of MRS2365 on the performance in the DNMTP task in comparison to ACSF-microinjected animals. MRS2365 was applied bilaterally into the $\mathrm{mPFC}$ at a dose of $0.05 \mathrm{pmol} / \mathrm{site}$, ACSF was given in the equivalent volume of $0.5 \mu \mathrm{l}$. Data (mean $\pm \mathrm{SEM} ; n=10$ for each group) are presented for delays of 0,8 and $16 \mathrm{~s}$ as percent correct responses (choice accuracy) (a), as percent correct responses if the same lever as in the previous trial was presented ('same trial') (b) and if the opposite lever as in the previous trial was presented ('different trial') $(c)$. $* P<0.05$, *** $P<0.0$ I, **** $P<0.00$ I versus ACSF. 

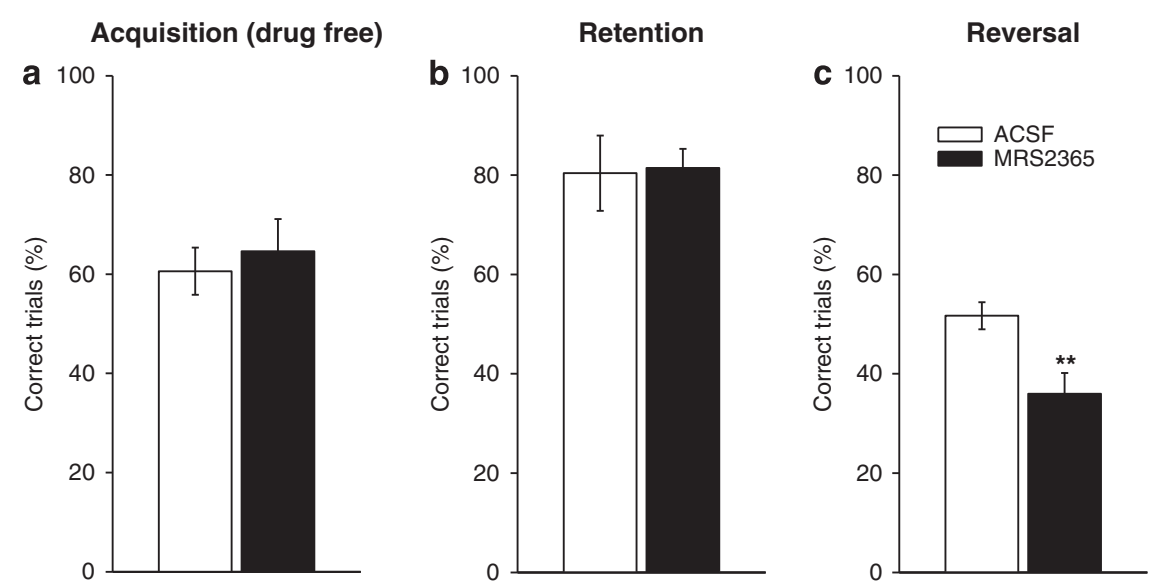

Figure 3 Effects MRS2365 on the performance in the reversal task. Percentage of correct trials is shown for the last acquisition session as well for retention and reversal sessions. Prior to retention and reversal sessions, MRS2365 was applied bilaterally into the mPFC at a dose of 0.05 pmol/side, ACSF was given in the equivalent volume of $0.5 \mu$. Data are presented as the mean \pm SEM (ACSF: $n=9$, MRS2365: $n=10$ ). $* * *<0.0$ I versus ACSF.

criterion compared to the MRS2365-group (2.4 \pm 0.6 versus $\left.4.5 \pm 0.6 ; \mathrm{F}_{1,17}=5.60, P=0.03\right)$. MRS2365-treatment during the reversal phase was associated with an increase in the number of uncompleted trials (omissions; ACSF group: $24.7 \pm 10.0$; MRS2365 group: $84.9 \pm 18.9, \mathrm{~F}_{1,17}=7.41$, $P=0.014)$.

\section{Microdialysis}

Basal concentrations of dopamine in the mPFC and NAc were found to be $0.22 \pm 0.05 \mathrm{fmol} / \mu \mathrm{l}$ and $0.41 \pm 0.16 \mathrm{fmol} / \mu \mathrm{l}$, respectively. MRS2365 caused a short-lasting increase in dopamine in the mPFC (Figure $4 \mathrm{a}$; treatment: $\mathrm{F}_{4,182}=16.00$, $P<0.001$; time: $\mathrm{F}_{12,182}=5.51, \quad P<0.001$; interaction: $\left.\mathrm{F}_{48,182}=1.72, P<0.01\right)$. MRS2365 $(1$ and $10 \mu \mathrm{M})$ increased dopamine at $40 \mathrm{~min}(1 \mu \mathrm{M}: P<0.001,10 \mu \mathrm{M}: P<0.01$; Figure $4 \mathrm{a})$ and at $60 \mathrm{~min}(1 \mu \mathrm{M}: P=0.02)$. Analysis of total dopamine $\left(\mathrm{AUC}_{0-180 \mathrm{~min}}\right)$ confirmed an inverted $\mathrm{U}$-shaped dose-effect relationship $\left(\mathrm{F}_{4,14}=5.98, P<0.01\right.$; Figure $\left.4 \mathrm{~b}\right)$ significant at $1 \mu \mathrm{M}$ MRS2365 $(P=0.01)$.

Infusion of MRS2365 into the MPFC increased dopamine in the NAc ( 0.1 and $1 \mu \mathrm{M} ; P<0.001$; Figure $4 \mathrm{c})$. There were significant effects of treatment $\left(\mathrm{F}_{4,182}=12.82, P<0.001\right)$, time $\left(\mathrm{F}_{12,182}=4.47, P<0.001\right)$ but no interaction $\left(\mathrm{F}_{48,182}=\right.$ $0.84, P=0.77)$. MRS2365 $(1 \mu \mathrm{M})$ increased dopamine from 40 min onwards $(P=0.02$; Figure $4 \mathrm{c})$. Total dopamine in the NAc also displayed an inverted U-shaped concentrationresponse pattern $\left(\mathrm{F}_{4,14}=3.40, P=0.04\right.$; Figure $\left.4 \mathrm{~d}\right)$ significant at $1 \mu \mathrm{M} \operatorname{MRS} 2365(P=0.03)$.

\section{Immunohistochemistry}

Immunohistochemistry in the mPFC with MAP2 (Figure 5a and $\mathrm{b}$ ) revealed that $\mathrm{P} 2 \mathrm{Y}_{1} \mathrm{Rs}$ are localized at neuronal structures, cell bodies and fibers. Double labeling with GFAP identified $\mathrm{P}_{2} \mathrm{Y}_{1}$ Rs also on astrocytic cell bodies and processes (Figure $5 \mathrm{c}$ and $\mathrm{d}$ ). Pyramidal cells of typical triangular shaped soma are endowed with $\mathrm{P}_{2} \mathrm{Y}_{1} \mathrm{Rs}$ (Figure $5 \mathrm{e}$ and $\mathrm{f}$ ). The co-localization of $\mathrm{P} 2 \mathrm{Y}_{1} \mathrm{Rs}$ and synaptophysin (Figure $5 \mathrm{~g}$ and $\mathrm{h}$ ) strongly argues for presynaptic $\mathrm{P} 2 \mathrm{Y}_{1} \mathrm{Rs}$, however not on TH-positive fibers (Figure $5 \mathrm{i}$ and $\mathrm{j}$ ). $\mathrm{P}_{2} \mathrm{Y}_{1} \mathrm{Rs}$ are localised at cell bodies and processes of GABA-containing neurons (Figure $5 \mathrm{k}$ and $\mathrm{l}$ ). These were parvalbuminpositive (Figure $5 \mathrm{~m}$ and $\mathrm{n}$ ) but not calretinin-positive interneurons (Figure 50 and p). $\mathrm{P}_{2} \mathrm{Y}_{1}$ Rs are also co-localized with vGLUT3, a marker for neurons releasing glutamate, but not primarily, in addition to acetylcholine, serotonin and even GABA (Figure 5q-s).

\section{DISCUSSION}

The present study provides experimental evidence suggesting for the first time that ATP/ADP-sensitive P2Rs in the $\mathrm{mPFC}$ may be involved in regulation of various behavioral functions. Stimulation of $\mathrm{P} 2 \mathrm{Y}_{1} \mathrm{Rs}$ by the selective agonist MRS2365 reduced PPI of the ASR, produced delaydependent decreases in accuracy in the DNMTP task, and impaired reversal learning. These effects may be mechanistically related to short- and long-lasting increases in dopamine in the $\mathrm{mPFC}$ and NAc, respectively, observed by microdialysis. $\mathrm{P} 2 \mathrm{Y}_{1}$ Rs were found on pyramidal cells and parvalbumin-positive interneurons but not on TH-positive fiber tracts originating in the VTA, which argues for an indirect activation of dopaminergic afferents in the cortex by MRS2365. As the importance of the rodent $\mathrm{mPFC}$ in executive functions, is widely accepted (for review see: Chudasama, 2011), alterations in prefrontal extracellular ATP/ADP transferred via $\mathrm{P}_{2} \mathrm{Y}_{1}$ Rs might be responsible for behavioral abnormalities such as observed in this study.

The PPI of the acoustic startle reflex reflects a preattentive filtering process known as sensorimotor gating. While the acoustic startle reflex is mediated by brainstem circuits and the spinal cord, it can be extensively modulated by the activity of limbic and cortico-pallido-striato-thalamic circuitries. In our study, stimulation of $\mathrm{P} 2 \mathrm{Y}_{1} \mathrm{Rs}$ in the mPFC by MRS2365 affected neither the mean ASR nor the habituation of the ASR, but significantly reduced PPI. The impaired PPI evoked by $\mathrm{P} 2 \mathrm{Y}_{1} \mathrm{R}$ stimulation has a profile consistent with prefrontal dopamine D1R inhibition with the exception that prefrontal dopamine was increased by local application of the agonist (Ellenbroek et al, 1996). 
mPFC
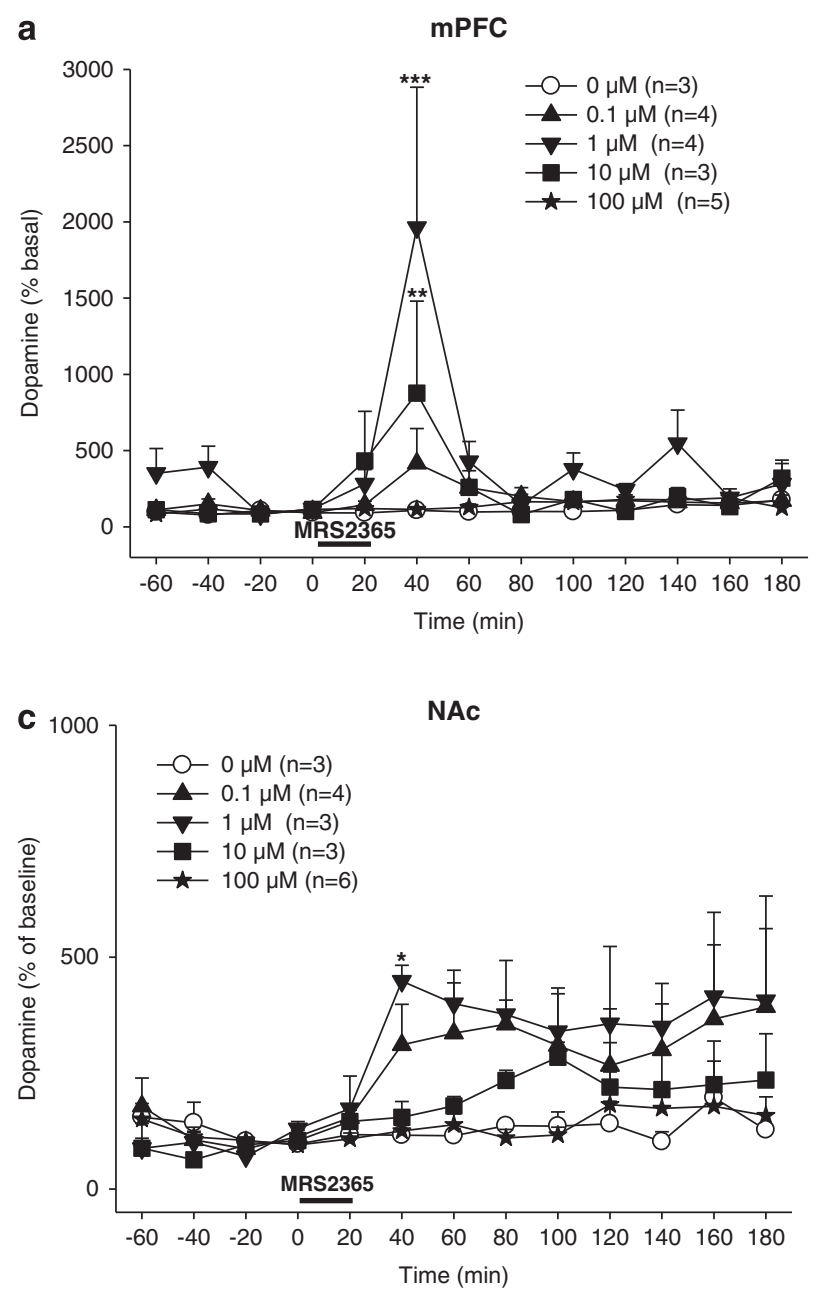

b $\quad$ AUC $_{(0-180)}-\mathrm{mPFC}$
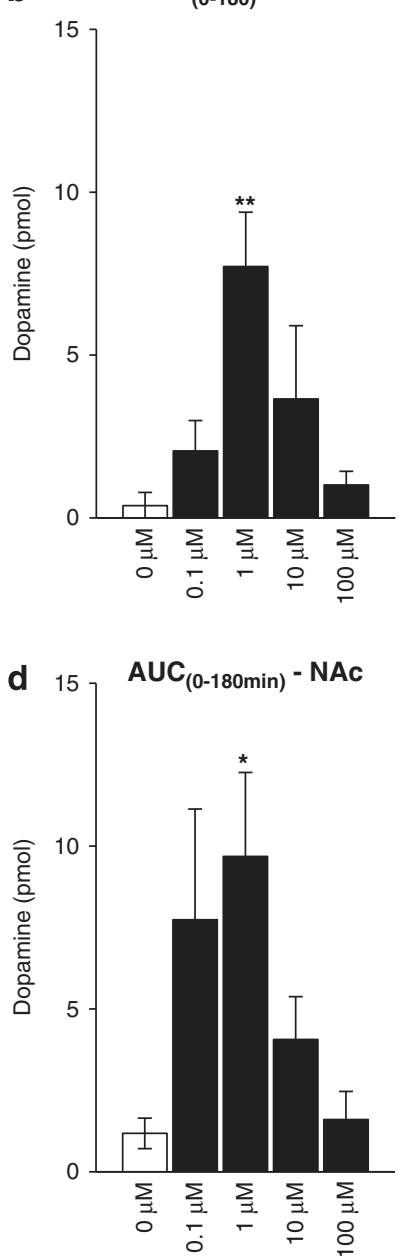

Figure 4 Effect of prefrontocortical infusion of MRS2365 on dopamine microdialysate concentrations in the mPFC (a and b) and in the ipsilateral NAc (c and d). MRS2365 was administered via retrodialysis in concentrations of $0.1,1.0,10$, and $100 \mu \mathrm{M}$ for 20 minutes each. Dopamine concentrations in microdialysates from the mPFC (a) and from NAc (c) after MRS2365-perfusion are presented as percent of basal concentration from the average of two pre-application levels. The total effect of MRS2365 on dopamine was calculated from the area under curve data collapsed over $0-180$ min based on percent baseline change in the mPFC (a) and NAc (d). Data are given as means \pm SEM. $* P<0.05, * * P<0.01$, $* * * P<0.001$ versus ACSF.

Similar disruptions of PPI were observed in rats after inactivation of the mPFC leading to subcortical dopaminergic hyperactivity, eg entorhinal cortex lesion or N-methyl-D-aspartate (NMDA)-R blockade (Goto et al, 2002; Suzuki et al, 2002). In line, D2 dopamine receptor agonists disrupt PPI (Swerdlow et al, 2005). Mesolimbic hyperactivity and cortical hypoactivity associated with abnormal PPI are assumed to be related to various aspects of neuropsychiatric disorders (Swerdlow et al, 2005).

Further, stimulation of $\mathrm{P}_{2} \mathrm{Y}_{1} \mathrm{Rs}$ by MRS2365 impaired accuracy of performance of the DNMTP task. Effects of MRS2365 were delay-dependent suggesting specific effects on aspects of rodent working memory assessed in this task. This conclusion is supported by analysis of accuracy in trials where the sample lever was similar to or different from that in the previous trial. Effects of MRS2365 were largely independent of the trial type indicating that treatment $\mathrm{d}$ id not induce side preference or increase probability of response perseveration. Interestingly, several other effects of MRS2365 were observed: decreased session length, increased frequency of magazine entries and the tendency of increased nose-poke rate. These effects may point at impaired response inhibition or impulse control induced by $\mathrm{P}_{2} \mathrm{Y}_{1} \mathrm{R}$-stimulation in PFC.

Involvement of prefrontal $\mathrm{P}_{2} \mathrm{Y}_{1} \mathrm{Rs}$ in the control of behavioral flexibility is verified by the reversal task results. Similar to what was observed in the DNMTP experiments, MRS2365 did not interfere with the performance of an already learned task. However, during the reversal phase, MRS2365 seemed to impair the ability of animals to switch responding to another lever. This was evident as reduced percentage of correct trials, more sessions needed to achieve the criterion and more uncompleted trials.

The mPFC controls executive functions via several mechanisms including modulation of accumbal dopamine (Del Arco and Mora, 2008; Taber et al, 1995; Floresco et al, 2009). Previous investigations have shown that local administration of $\mathrm{P} 2 \mathrm{Y}_{1} \mathrm{R}$ agonists into NAc or VTA facilitates while antagonists decrease the release of dopamine under basal conditions (Krügel et al, 2001a; Krügel 

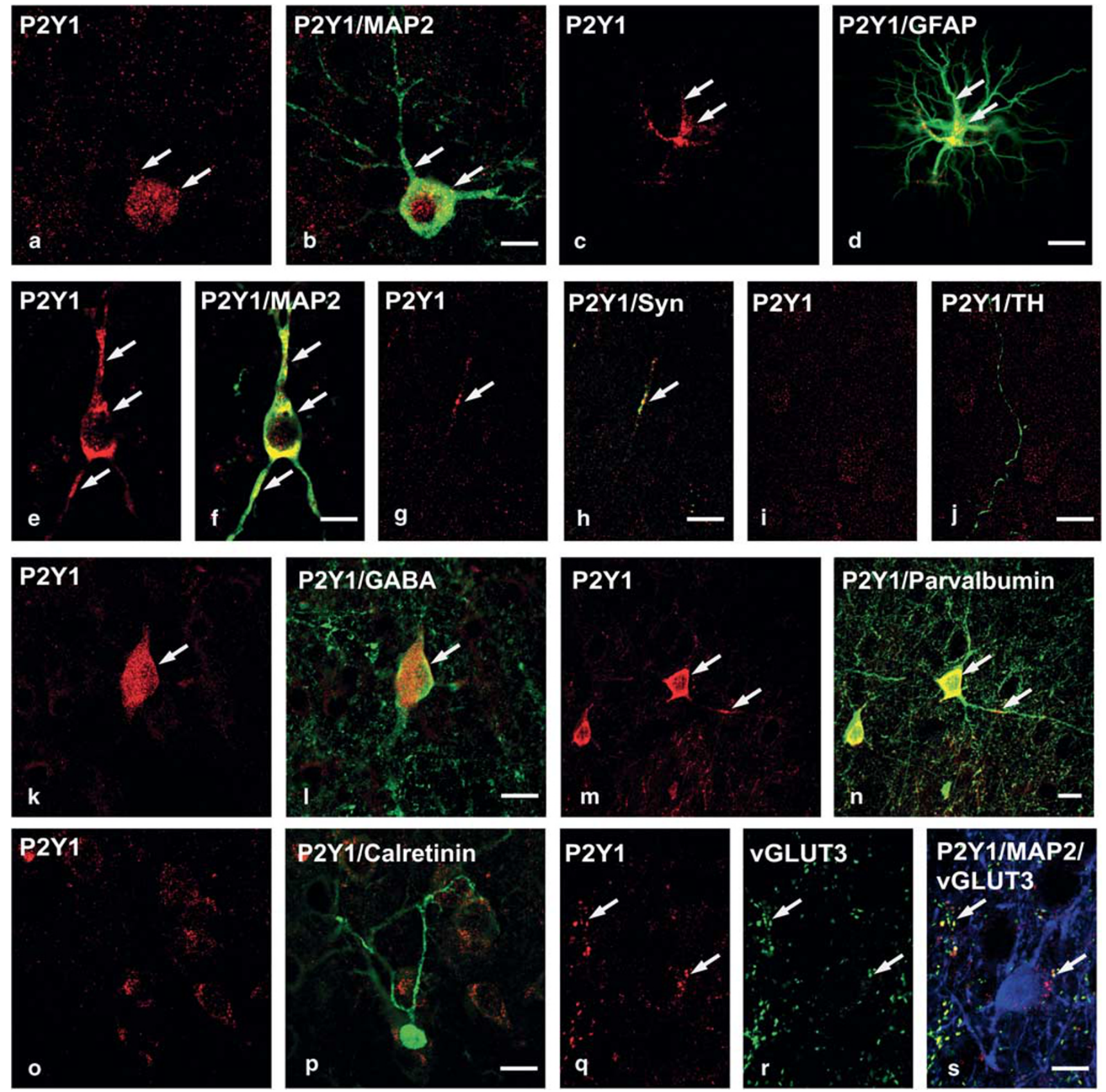

Figure 5 Immunocytochemical identification of P2Y, R-localisation in prefrontocortical layer $\mathrm{V}$. P2Y, Rs (red) are localized on neuronal structures labeled with MAP2 (green; $a$ and b) and on astrocytes identified by GFAP-labeling (green; $c$ and d). Neurons with the typical triangular shape of pyramidal cells (e and f) bear P2Y, Rs at the apical dendrite (upper arrow), at the cell body (middle arrow) and at basal dendrites (lower arrow). P2Y,Rs are presynaptically located as indicated by co-labeling with synaptophysin, see arrow (green; $g$ and $h$ ) but not on TH-positive fibers ( $i$ and $j$ ). Further, P2Y, Rs were found on GABA-containing neurons (green; $k$ and $I$ ) and parvalbumin-positive neurons (green; $m$ and $n$ ) at cell bodies and origin of processes. Calretinin-positive neurons ( $O$ and $p$ ) were not labeled for P2Y, Rs. Finally, P2Y,Rs were co-localized with dot-like vGLUT3 structures (green; $q, r$ and s) and in strong association with the neuronal marker MAP2 (blue) as indicated by arrows. Scale bars $=10 \mu \mathrm{m}$.

et al, 2001b; Kittner et al, 2004). Our microdialysis data demonstrate that stimulation of prefrontal $\mathrm{P}_{2} \mathrm{Y}_{1} \mathrm{Rs}$ also increased subcortical dopamine in the NAc. An inverted U-shaped dose-dependency of purine-mediated effects on dopamine is similar to that reported in earlier studies on stimulation of phosphoinositide hydrolysis in NG108-15 cells by the $\mathrm{P} 2 \mathrm{Y}_{1,12}$ agonists, ADP $\beta S$ and $2 \mathrm{MeSADP}$, and on exploratory activity by 2-methylthio-ATP (Kittner et al, 2000; Sak et al, 2000) or MRS2365 (present study).
Dopamine facilitating effects by MRS2365 were more pronounced and short-lasting in the mPFC compared to the NAc where dopamine was elevated for a much longer time similar to effects after NMDA-R antagonist microinjection (Del Arco and Mora, 2009).

It is known that working memory depends on dopamine in the PFC, however the relationship between dopamine and working memory performance is not linear and its inverted U-shape was suggested to indicate existence of 
dopaminergic activity optimal for the function of PFC (van Schouwenburg et al, 2010; Arnsten, 2009; Floresco et al, 2009). The acute transient activation of prefrontal $P 2 Y_{1} R s$ seems to trigger the deviation from optimal dopamine in the mPFC and this might contribute to the observed behavioral effects, eg decreased behavioral flexibility (van Schouwenburg et al, 2010; Floresco et al, 2009). Thus, even though present behavioral and microdialysis studies were conducted in rats of two different strains for which differences in the sensitivity to PPI-disrupting effects are reported (Swerdlow et al, 2000), microdialysis results support the behavioral relevance of the used dose of MRS2365 in operant tasks as it matches the most effective dopamine-enhancing concentration of $1 \mu \mathrm{M}$ (assuming a recovery of $10 \%$ for MRS2365 at the membrane similar to ATP; Krügel et al, 2001b). Similar relationships between dose (behavior) and concentration (microdialysis) were found for the less selective agonist 2-methylthio-ATP in the ventral tegmentum (Krügel et al, 2001a).

MRS2365-induced increase in prefrontal dopamine and related behavioral responses do not seem to be mediated by direct presynaptic $\mathrm{P} 2 \mathrm{Y}_{1} \mathrm{R}$-stimulation on dopaminergic terminals as no $\mathrm{P}_{2} \mathrm{Y}_{1} \mathrm{R}$-immunoreactivity was found on prefrontal TH-positive fibers. Therefore, multisynaptic mechanisms are suggested to be involved. Our immunohistochemical data provide evidence for $\mathrm{P}_{2} \mathrm{Y}_{1} \mathrm{R}$-positive subpopulations of $\mathrm{MPFC}$ neurons, which had morphological features of pyramidal cells or were positive for GABA or parvalbumin.

Previous slice studies have already revealed the presence of functionally active prefrontal postsynaptic $\mathrm{P}_{2} \mathrm{Y}_{1} \mathrm{Rs}$ on pyramidal cells (Luthardt et al, 2003). As these cells are known to synapse in the VTA onto dopamine neurons that project back to the $\mathrm{mPFC}$, the stimulation of $\mathrm{P}_{2} \mathrm{Y}_{1} \mathrm{Rs}$ might activate the mPFC-VTA-mPFC circuit (Carr and Sesack, 2000). In line with that, the firing rate of dopamine neurons can be regulated depending upon glutamatergic stimulation within the VTA (Wang et al, 1994). Dopamine neurons have synaptic contacts within the VTA with GABA interneurons and GABA neurons projecting to the NAc. Thereby, prefrontal $\mathrm{P}_{2} \mathrm{Y}_{1}$ Rs might modulate the activity of mesoaccumbal neurons and dopamine release in the NAc indirectly (Carr and Sesack, 2000). This hypothesis is supported by facilitating effects of the $\mathrm{GABA}_{\mathrm{A}} \mathrm{R}$-antagonist bicuculline infused into the VTA on dopamine in the NAc (Krügel et al, 2001a). Furthermore, mPFC neurons also may facilitate accumbal dopamine by an indirect pathway involving the pedunculo pontine tegmentum and the laterodorsal tegmentum, which in turn stimulate mesoaccumbal projection neurons (Del Arco and Mora, 2008).

Behavioral alterations induced by MRS2365 in the present study are similar to motor hyperactivity and cognitive impairment found after inhibition of prefrontal NMDA-Rs with phencyclidine (Del Arco et al, 2008). NMDA-R antagonists such as 3-[(R)-2-carboxypiperazin-4-yl]-propyl-1-phosphonic acid (CPP) applied to the PFC caused lasting elevations of accumbal dopamine providing evidence that hypofunction of prefrontal NMDA-Rs produces corticolimbic hyperactivity by activation of subcortical areas (Del Arco et al, 2008).

Interestingly, at PFC layer 5 pyramidal cells, the activation of $\mathrm{P}_{2} \mathrm{Y}_{1} \mathrm{Rs}$ inhibited both, the current responses to
NMDA and the NMDA-component of excitatory postsynaptic potentials evoked by electrical stimulation (Luthardt et al, 2003). The nature of that interaction at pyramidal cells or GABA interneurons (see below) is unclear. Heteromers, similar to $\mathrm{A}_{2 \mathrm{~A}} \mathrm{R}-\mathrm{D} 2 \mathrm{R}$, as well ion channel receptor-receptor tyrosine kinase heteromers possibly might be involved (Agnati et al, 2010). At all, this interference is similar to the action of NMDA-R antagonists and might have impact on the activity of pyramidal cells. It is suggested that NMDA-R blockade increases the activity of pyramidal efferent projections by attenuation of feedback inhibition by GABA interneurones endowed with NMDA-Rs (Del Arco et al, 2011; Homayoun and Moghaddam, 2007).

Further, P2YRs on non-pyramidal cells strongly argue for their participation in prefrontal disinhibition. Among $\mathrm{P} 2 \mathrm{Y}_{1} \mathrm{R}$-positive non-pyramidal cells, we identified GABApositive and parvalbumin-, but not calretinin-positive neurons. Given that parvalbumin and calretinin expression characterizes different classes of interneurones, $\mathrm{P}_{2} \mathrm{Y}_{1} \mathrm{Rs}$ might have specific functions in prefrontal inhibition (Kawaguchi and Kubota, 1998).

Calretinin-containing interneurons are suggested to mediate the overall network disinhibition in the PFC because they preferentially target dendrites of other GABA neurons rather than pyramidal cells (Hashimoto et al, 2003).

Parvalbumin interneurons primarily contact soma and axon initial segments of pyramidal cells and thereby deliver a unique inhibitory input to them (Marin, 2012). Fast-spiking parvalbumin interneurons are involved in oscillatory activity, which enables pyramidal cells to fire synchronously and is crucial for cognitive functions. Alterations in parvalbumin neuron-mediated inhibition are attributed to cognitive deficits in schizophrenia (Gonzalez-Burgos and Lewis, 2008). The observed behavioral changes by MRS2365 and the expression of $\mathrm{P}_{2} \mathrm{Y}_{1} \mathrm{Rs}$ on parvalbumin interneurons fit in this concept.

Whereas Guzman et al (2010) identified postsynaptic $\mathrm{P} 2 \mathrm{Y}_{1} \mathrm{Rs}$, the co-localization with synaptophysin, an integral membrane glycoprotein of small synaptic vesicles, also confirms a presynaptic function, probably in the modulation of transmitter release.

A co-expression of $\mathrm{P}_{2} \mathrm{Y}_{1} \mathrm{Rs}$ and vGLUT3 in strong association with neuronal structures was also observed suggesting a contribution of $\mathrm{P}_{2} \mathrm{Y}_{1} \mathrm{Rs}$ to the neuronal release of glutamate from cortical neurons not primarily glutamatergic, eg GABA interneurones or excitatory interneurones (Herzog et al, 2004; Franke et al, 2006). Even though the significance of $\mathrm{P}_{2} \mathrm{Y}_{1} \mathrm{Rs}$ in this interaction is completely unknown, the vGLUT-dependent increased vesicular accumulation of primary neurotransmitters (vesicular synergy) proposed by El Mestikawy et al (2011) is a conceivable mechanism of ATP/ADP contribution to GABA/glutamate co-transmission and thereby to the modulation of prefrontal synaptic activity.

In conclusion, the results indicate the involvement of $\mathrm{P}_{2} \mathrm{Y}_{1} \mathrm{Rs}$ in the prefrontal cortical control over certain cognitive behavioral responses. This control may become more significant under conditions of augmented ADPsignaling (eg after prolonged exhausting network activity, associated with neuroinflammation or neuronal injury). 


\section{FUNDING AND DISCLOSURE}

Role of funding source: These studies were funded by the "Interdisziplinäres Zentrum für Klinische Forschung" of the University of Leipzig (IZKF, C31), the "Deutsche Forschungsgemeinschaft" KI 677/4-2. HK was supported by a stipend from AbbVie Deutschland $\mathrm{GmbH}$ \& Co KG. The funding had no further role in study design, collection, analysis or interpretation of data or in submission of the manuscript. The authors declare no conflict of interest.

\section{ACKNOWLEDGEMENTS}

We grateful acknowledge the excellent technical assistance of Mrs Anne-Kathrin Krause, Mrs Katrin Becker and Mr Lutz Feige.

\section{Author Contributions}

$A B$ and $U K$ designed the study. HK performed the behavioral experiments and statistical analysis. KD conducted the microdialysis, HF managed the immunohistochemistry. $\mathrm{HK}, \mathrm{AB}$ and $\mathrm{UK}$ prepared the main parts of the manuscript, which was approved by all authors.

\section{REFERENCES}

Abbracchio MP, Burnstock G, Verkhratsky A, Zimmermann H (2009). Purinergic signalling in the nervous system: an overview. Trends Neurosci 32: 19-29.

Agnati LF, Guidolin D, Leo G, Carone C, Genedani S, Fuxe K (2010). Receptor-receptor interactions: A novel concept in brain integration. Prog Neurobiol 90: 157-175.

Arnsten AF (2009). Toward a new understanding of attentiondeficit hyperactivity disorder pathophysiology: an important role for prefrontal cortex dysfunction. CNS Drugs 23(Suppl 1): 33-41.

Arnsten AF, Rubia K (2012). Neurobiological circuits regulating attention, cognitive control, motivation, and emotion: disruptions in neurodevelopmental psychiatric disorders. J Am Acad Child Adolesc Psychiatry 51: 356-367.

Bodin P, Burnstock G (2001). Purinergic signalling: ATP release. Neurochem Res 26: 959-969.

Boulougouris V, Robbins TW (2010). Enhancement of spatial reversal learning by 5 -HT2C receptor antagonism is neuroanatomically specific. J Neurosci 30: 930-938.

Burnstock G, Krügel U, Abbracchio MP, Illes P (2011). Purinergic signalling: From normal behaviour to pathological brain function. Prog Neurobiol 95: 229-274.

Carr DB, Sesack SR (2000). Projections from the rat prefrontal cortex to the ventral tegmental area: target specificity in the synaptic associations with mesoaccumbens and mesocortical neurons. J Neurosci 20: 3864-3873.

Chandaka GK, Salzer I, Drobny H, Boehm S, Schicker KW (2011). Facilitation of transmitter release from rat sympathetic neurons via presynaptic $\mathrm{P} 2 \mathrm{Y}(1)$ receptors. Br J Pharmacol 164: 1522-1533.

Chhatriwala M, Ravi RG, Patel RI, Boyer JL, Jacobson KA, Harden TK (2004). Induction of novel agonist selectivity for the ADP-activated P2Y1 receptor versus the ADP-activated $\mathrm{P} 2 \mathrm{Y} 12$ and $\mathrm{P} 2 \mathrm{Y} 13$ receptors by conformational constraint of an ADP analogue. J Pharmacol Exp Ther 311: 1038-1043.

Chudasama Y (2011). Animal models of prefrontal-executive function. Behav Neurosci 125: 327-343.
Del Arco A, Mora F (2009). Neurotransmitters and prefrontal cortex-limbic system interactions: implications for plasticity and psychiatric disorders. J Neural Transm 116: 941-952.

Del Arco A, Mora F (2008). Prefrontal cortex-nucleus accumbens interaction: in vivo modulation by dopamine and glutamate in the prefrontal cortex. Pharmacol Biochem Behav 90: 226-235.

Del Arco A, Ronzoni G, Mora F (2011). Prefrontal stimulation of GABAA receptors counteracts the corticolimbic hyperactivity produced by NMDA antagonists in the prefrontal cortex of the rat. Psychopharmacology (Berl) 214: 525-536.

Del Arco A, Segovia G, Mora F (2008). Blockade of NMDA receptors in the prefrontal cortex increases dopamine and acetylcholine release in the nucleus accumbens and motor activity. Psychopharmacology (Berl) 201: 325-338.

El Mestikawy S, Wallen-Mackenzie A, Fortin GM, Descarries L, Trudeau LE (2011). From glutamate co-release to vesicular synergy: vesicular glutamate transporters. Nat Rev Neurosci 12: 204-216.

Ellenbroek BA, Budde S, Cools AR (1996). Prepulse inhibition and latent inhibition: the role of dopamine in the medial prefrontal cortex. Neuroscience 75: 535-542.

Fischer W, Krügel U (2007). P2Y receptors: Focus on structural, pharmacological and functional aspects in the brain. Curr Med Chem 14: 2429-2455.

Floresco SB, Zhang Y, Enomoto T (2009). Neural circuits subserving behavioral flexibility and their relevance to schizophrenia. Behav Brain Res 204: 396-409.

Franke H, Grummich B, Härtig W, Grosche J, Regenthal R, Edwards RH et al (2006). Changes in purinergic signaling after cerebral injury-involvement of glutamatergic mechanisms? Int J Dev Neurosci 24: 123-132.

Goldstein RZ, Volkow ND (2011). Dysfunction of the prefrontal cortex in addiction: neuroimaging findings and clinical implications. Nat Rev Neurosci 12: 652-669.

Gonzalez-Burgos G, Lewis DA (2008). GABA neurons and the mechanisms of network oscillations: implications for understanding cortical dysfunction in schizophrenia. Schizophr Bull 34: 944-961.

Goto K, Ueki A, Iso H, Morita Y (2002). Reduced prepulse inhibition in rats with entorhinal cortex lesions. Behav Brain Res 134: 201-207.

Guzman SJ, Schmidt H, Franke H, Krügel U, Eilers J, Illes P et al (2010). P2Y1 receptors inhibit long-term depression in the prefrontal cortex. Neuropharmacology 59: 406-415.

Hashimoto T, Volk DW, Eggan SM, Mirnics K, Pierri JN, Sun Z et al (2003). Gene expression deficits in a subclass of GABA neurons in the prefrontal cortex of subjects with schizophrenia. J Neurosci 23: 6315-6326.

Heinrich A, Ando RD, Turi G, Rozsa B, Sperlagh B (2012). K ${ }^{+}$ depolarization evokes ATP, adenosine and glutamate release from glia in rat hippocampus: a microelectrode biosensor study. Br J Pharmacol 167: 1003-1020.

Herzog E, Gilchrist J, Gras C, Muzerelle A, Ravassard P, Giros B et al (2004). Localization of VGLUT3, the vesicular glutamate transporter type 3, in the rat brain. Neuroscience 123: 983-1002.

Homayoun H, Moghaddam B (2007). NMDA receptor hypofunction produces opposite effects on prefrontal cortex interneurons and pyramidal neurons. J Neurosci 27: 11496-11500.

Kawaguchi Y, Kubota Y (1998). Neurochemical features and synaptic connections of large physiologically-identified GABAergic cells in the rat frontal cortex. Neuroscience 85: 677-701.

Khakh BS, Gittermann D, Cockayne DA, Jones A (2003). ATP modulation of excitatory synapses onto interneurons. J Neurosci 23: 7426-7437.

Kittner H, Krügel U, Hoffmann E, Illes P (2000). Effects of intra-accumbens injection of 2-methylthio ATP: a combined open field and electroencephalographic study in rats. Psychopharmacology (Berl) 150: 123-131. 
Kittner H, Krügel U, Hoffmann E, Illes P (2004). Modulation of feeding behaviour by blocking purinergic receptors in the rat nucleus accumbens: a combined microdialysis, electroencephalographic and behavioural study. Eur J Neurosci 19: 396-404.

Krügel U, Kittner H, Franke H, Illes P (2001a). Stimulation of P2 receptors in the ventral tegmental area enhances dopaminergic mechanisms in vivo. Neuropharmacology 40: 1084-1093.

Krügel U, Kittner H, Franke H, Illes P (2003). Purinergic modulation of neuronal activity in the mesolimbic dopaminergic system in vivo. Synapse 47: 134-142.

Krügel U, Kittner H, Illes P (2001b). Mechanisms of adenosine 5'-triphosphate-induced dopamine release in the rat nucleus accumbens in vivo. Synapse 39: 222-232.

Lüscher C, Malenka RC (2011). Drug-evoked synaptic plasticity in addiction: from molecular changes to circuit remodeling. Neuron 69: 650-663.

Luthardt J, Borvendeg SJ, Sperlagh B, Poelchen W, Wirkner K, Illes $\mathrm{P}$ (2003). P2Y1 receptor activation inhibits NMDA receptorchannels in layer $\mathrm{V}$ pyramidal neurons of the rat prefrontal and parietal cortex. Neurochem Int 42: 161-172.

Marin O (2012). Interneuron dysfunction in psychiatric disorders. Nat Rev Neurosci 13: 107-120.

Nikiforuk A, Popik P, Drescher KU, van Gaalen M, Relo AL, Mezler M et al (2010). Effects of a positive allosteric modulator of group II metabotropic glutamate receptors, LY487379, on cognitive flexibility and impulsive-like responding in rats. J Pharmacol Exp Ther 335: 665-673.

Pankratov Y, Lalo U, Verkhratsky A, North RA (2006). Vesicular release of ATP at central synapses. Pflügers Arch 452: 589-597.

Pintor J, Porras A, Mora F, Miras-Portugal MT (1995). Dopamine receptor blockade inhibits the amphetamine-induced release of diadenosine polyphosphates, diadenosine tetraphosphate and diadenosine pentaphosphate, from neostriatum of the conscious rat. J Neurochem 64: 670-676.

Sak K, Barnard EA, Jarv J (2000). Dual effect of nucleotides on P2Y receptors. IUBMB Life 50: 99-103.
Schneider M, Drews E, Koch M (2005). Behavioral effects in adult rats of chronic prepubertal treatment with the cannabinoid receptor agonist WIN 55,212-2. Behav Pharmacol 16: 447-454.

Seamans JK, Lapish CC, Durstewitz D (2008). Comparing the prefrontal cortex of rats and primates: insights from electrophysiology. Neurotox Res 14: 249-262.

Sukhotina IA, Dravolina OA, Novitskaya Y, Zvartau EE, Danysz W, Bespalov AY (2008). Effects of mGlul receptor blockade on working memory, time estimation, and impulsivity in rats. Psychopharmacology (Berl) 196: 211-220.

Suzuki Y, Jodo E, Takeuchi S, Niwa S, Kayama Y (2002). Acute administration of phencyclidine induces tonic activation of medial prefrontal cortex neurons in freely moving rats. Neuroscience 114: 769-779.

Swerdlow NR, Martinez ZA, Hanlon FM, Platten A, Farid M, Auerbach P et al (2000). Toward understanding the biology of a complex phenotype: rat strain and substrain differences in the sensorimotor gating-disruptive effects of dopamine agonists. J Neurosci 20: 4325-4336.

Swerdlow NR, Shoemaker JM, Bongiovanni MJ, Neary AC, Tochen LS, Saint Marie RL (2005). Reduced startle gating after D1 blockade: effects of concurrent D2 blockade. Pharmacol Biochem Behav 82: 293-299.

Taber MT, Das S, Fibiger HC (1995). Cortical regulation of subcortical dopamine release: mediation via the ventral tegmental area. J Neurochem 65: 1407-1410.

van Schouwenburg M, Aarts E, Cools R (2010). Dopaminergic modulation of cognitive control: distinct roles for the prefrontal cortex and the basal ganglia. Curr Pharm Des 16: 2026-2032.

Waldo GL, Harden TK (2004). Agonist binding and Gq-stimulating activities of the purified human P2Y1 receptor. Mol Pharmacol 65: 426-436.

Wang T, O'Connor WT, Ungerstedt U, French ED (1994). $\mathrm{N}$-methyl-D-aspartic acid biphasically regulates the biochemical and electrophysiological response of A10 dopamine neurons in the ventral tegmental area: in vivo microdialysis and in vitro electrophysiological studies. Brain Res 666: 255-262.

Supplementary Information accompanies the paper on the Neuropsychopharmacology website (http://www.nature.com/npp) 